\title{
Utilization of services provided by village based ethnic minority midwives in mountainous villages of Vietnam
}

This article was published in the following Dove Press journal:

International Journal of Women's Health

20 October 2016

Number of times this article has been viewed

\author{
Duong Thi Thuy Doan' \\ Ha Thi Thu Bui' \\ Thi Minh Le' \\ Duc Minh Duong' \\ Hong Thi Luu ${ }^{2}$ \\ Tuan Anh Dinh ${ }^{2}$ \\ Tolib Mirzoev ${ }^{3}$ \\ 'Department of Reproductive \\ Health, Hanoi School of Public \\ Health, ${ }^{2}$ Department of Maternal \\ and Child Health, Ministry of \\ Health, Hanoi, Vietnam; ${ }^{3}$ Nuffield \\ Centre for International Health \\ and Development, Leeds Institute \\ of Health Sciences, University \\ of Leeds, Leeds, UK
}

Introduction: Since 2011, the Vietnam's Ministry of Health implemented the ethnic minority midwives (EMMs) scheme in order to increase the utilization of maternal health services by women from ethnic minorities and those living in hard-to-reach mountainous areas. This paper analyzes the utilization of antenatal, delivery, and postpartum care provided by EMMs and reports the key determinants of utilization of EMM services as perceived by service users.

Methods: A structured questionnaire was administered in 2015 to all mothers $(n=320)$ who gave birth to a live-born during a 1-year period in 31 villages which had EMM in two provinces, Dien Bien and Kon Tum. A multivariate logistic regression model was used to examine the association between all potential factors and the use of services provided by EMMs.

Results: We found that EMMs provided more antenatal care and postnatal care as compared with delivery services, which corresponded to their job descriptions. The results also showed that utilization of antenatal care provided by EMMs was lower than that of postnatal care. The proportion of those who never heard about EMM was high (24\%). Among the mothers who knew about EMM services, 33.4\% had antenatal checkups, 20.1\% were attended during home deliveries, and $57.3 \%$ had postnatal visits by an EMM. Key factors that determined the use of EMM services included knowledge of the location of EMM's house, being aware about EMMs by health workers, trust in services provided by EMMs, and perception that many others mothers in a village also knew about EMM services.

Conclusion: EMM seems to be an important mechanism to ensure assistance during home births and postnatal care for ethnic minority groups, who are often resistant to attend health facilities. Building trust and engaging with communities are the key facilitators to increase the utilization of services provided by EMMs. Communication campaigns to raise awareness about EMMs and to promote their services in the village, particularly by other health workers, represent an important strategy to further improve effectiveness of EMM scheme.

Keywords: safe motherhood services, midwifery training, ethnic minority

\section{Introduction}

Maternal mortality has been reducing from 140 in 1990 to 49 in 2013 in Vietnam. ${ }^{1}$ Although national-level health indicators have improved, nowadays the distribution of four or more antenatal care (ANC) visits and skilled birth attendance rate remain highly inequitable. ${ }^{2}$ Disparities between ethnic minority groups who mostly inhabit rural, mountainous areas, and Kinh/Hoa (majority ethnicity) are substantial and are likely to increase over time..$^{2-5}$ For example, in 2006 the risk of not giving birth in a health facility between women from ethnic minority groups in rural areas was nearly five times higher than that of women of majority ethnicity, and in 2010-2011 such risk rose to $\sim 20$ times higher. $^{6}$
Correspondence: Duong Thi Thuy Doan Department of Reproductive Health, Hanoi School of Public Health,

I 38 Giang Vo, Ba Dinh, Hanoi, Vietnam

Tel +8462662320

Email dttd@hsph.edu.vn 
During 2011-2015, the National Targeted Programme on Safe Motherhood introduced training of local young ethnic women to become village midwives, referred as ethnic minority midwives (EMMs). This was implemented in recognition of the need to address the shortage of human resources and improve utilization of maternal health services by ethnic minority groups. In 2013, the Ministry of Health (MOH) officially recognized EMMs as village health workers with monthly salary payments and approved a 6-month training program as a unified approach, to ensure its consistency with training of village health workers in Vietnam. This training does not equate to the regular midwifery education in medical schools, and the idea is that EMMs who share the same language, culture, values, and beliefs would gain trust and encourage local women to use more maternal health services.

The participants for this training were chosen from villages where ethnic minorities normally resided, in order to ensure that they speak the same language, are familiar with local culture, and remain accessible to the communities. The trainees were selected from three groups: 1) those who were not previously trained as a health worker, 2) those who were working as village health workers, and 3) those who had been trained under a predecessor program for EMMs. ${ }^{7}$

The contents of training for EMMs covered the following topics: ANC checkups, ANC counseling, attendance of home deliveries, postnatal care (PNC) home visits within 42 days after delivery, postnatal counseling, neonatal counseling, and support and referral to higher level of health-care facilities (eg, community health center, district hospital, and provincial hospital) in cases of abnormal signs or symptoms in either a mother or a newborn. This enabled the EMMs to provide basic maternal health services, free of charge, in their respective villages as outlined in the Ministry of Health Circular (No 07/2013/TTBYT). More details of this training program had been published elsewhere. ${ }^{?}$

As part of their work, an EMM was required to report their activities to a midwife during monthly meetings at community health centers, so that midwives could then advise EMMs on any difficulties they faced. In 2014, over 1,700 EMMs received at least 6 months training, which provided EMMs for $20 \%$ of 8,576 villages in poor and hardto-reach mountainous areas where women had difficulties in accessing safe motherhood services. ${ }^{8}$

Experiences of training of local women to become skilled birth attendants to increase the utilization of maternal services in difficult-to-reach areas also exist elsewhere. Similar schemes were found to be effective in Upper East Region of Ghana, ${ }^{9}$ Indonesia, ${ }^{10}$ Sichuan Province, China, ${ }^{11}$ and in rural, hard-to-reach, and marginalized groups in Tibet. ${ }^{12}$ In Vietnam, the EMM pilot scheme appeared promising and contributed to the improvement of health of mothers and their newborns. ${ }^{7}$ Other studies, however, found that services provided by EMMs can be framed by medicalized training and distanced from local birth culture and norms, ${ }^{13}$ suggesting that services offered by EMMs may not be always accepted by local communities and local health facilities, possibly due to low awareness of their existence and low support to the EMM performance.

Evidence on utilization of services provided by EMMs in Vietnam is still preliminary. The objectives of this study are therefore to 1) analyze the utilization of EMM services at various stages of maternal care (ANC, delivery, and PNC) in mountainous villages of two provinces and 2) identify factors that determine the utilization of services provided by EMMs. We expect that this paper will be of interest to different audiences (such as policymakers, program managers, and researchers), in Vietnam and more internationally, who are considering different approaches to improve access to health services to marginalized population groups.

\section{Methods}

\section{Study setting and sampling}

The study was conducted in two provinces, representing two main highland regions of Vietnam: Dien Bien (in the Northwest region) and Kon Tum (in the Central Highland region). These two provinces were chosen because they are among the poorest provinces in the hard-to-reach mountainous regions of Vietnam, with each having proportion of ethnic minority groups comprising $50 \%-80 \%$ of their populations. Maternal health outcomes and service utilization rates in these two provinces are among the lowest in their respective regions. In 2013, the ANC coverage (at least three visits) was approximately $52 \%$ and $79 \%$ and institutional delivery rate was $69 \%$ and $76.7 \%$ in Dien Bien and Kon Tum, respectively. ${ }^{8}$

In each province, two districts (total $n=4$ ) and then two communes, that is, a subdistrict level comprising groups of villages (total $n=8$ ) from each district that had EMMs working in their respective villages were selected. In each district, one selected commune had the highest rate of uptake of institutional deliveries and other the lowest. A total of 31 villages from eight communes, all of which had a total of 31 EMMs, were included in the study. Of these 31 EMMs, 23 had completed their training 5 months prior to the assessment. The remaining eight EMMs had completed their training $>2$ years prior to the assessment. The sample size was determined by a single population proportion formula 
with the following assumptions: level of confidence of the study $95 \%$, sampling error tolerated $4 \%$, proportion $(P)$ of women who use any EMM services was 50\%, nonresponse rate $10 \%$, and design effect of 2 . All 350 women who gave birth to a live-born during the last 1 year before the study and were living in villages where EMMs operated were invited to participate in the study.

\section{Data collection}

All data were collected in 2015 using a structured questionnaire. Four interviewers, two researchers from Hanoi School of Public Health and two health staff members from the Provincial Reproductive Health Centers, were trained before collecting data. All interviewers were women, to ensure comfort and encourage ethnic minority women to share their experiences in accessing maternal and child health care. Community health workers had invited these mothers, who came to community health centers where the interviews were held. A total of 320 out of 350 invited women (91.4\%) participated in the study. Majority of ethnic minority women could understand Viet language (which is an official language in Vietnam), and for those who could not understand, the other ethnic minority women, women village health workers, or community health workers helped with interpretation.

\section{Measurements}

The outcome variable, using any EMM services, was defined as using any of seven maternal health services, which were determined in the Ministry of Health Circular (No 07/2013/ TTBYT) mentioned earlier. Respondents was interviewed about maternal health care services utilization of their last delivery and those services provided by whom. The use of any EMM services was determined by any maternal health services provided by EMM. Regarding ANC checkups, for example, the respondents were asked "Did you have ANC checkups?" If the response to this question was yes, then a follow-up question "Who provided your ANC checkup?" was asked with multiple choices of answers: a doctor, a nurse, an EMM, a village health worker, and another health worker (specify).

Potential factors associated with using any EMM services were divided into three categories: sociodemographic characteristics, knowledge and trust in EMM services, and ability to reach EMM services.

- Sociodemographic characteristics included variables on age $(<20$ and $>20$ ), number of children (one child or more), mother's education (attended school or not), ethnic minority group (Hmong, Kho Mu, or Khang in Dien Bien as compared with Xo Dang, Ba Na, or Gia Lai in Kon
Tum province), and household economic status (poor or nonpoor, using government poverty threshold of monthly household income of 400,000 VND $\approx$ US\$20).

- Knowledge and trust in EMM services included variables on awareness about EMM services $(<4 / 7$ and at least 4/7 services), knowing that EMM was trained; source of information about EMMs, knowledge of other mothers in the village who know about an EMM, knowing the location of EMM house, and trust in EMM services. Trust in EMM services was dichotomized into two groups: trust in some of EMM service provision $(<4 / 7)$ and trust in most of EMM service provisions (at least 4/7).

- Ability to reach EMM services included distance to nearest health facilities ( $<5 \mathrm{~km}$ and $>5 \mathrm{~km}$ ), having difficult seasonal access to the nearest health facilities, distance to EMM house $(<2 \mathrm{~km}$ and $>2 \mathrm{~km})$, and calling EMM if needed.

A questionnaire was pretested and subsequently revised to fit the context of the ethnic minority group.

\section{Data analysis}

All statistical analyses were performed using SPSS version 20 (IBM Corporation, Armonk, NY, USA). After examining the data, records on 76 mothers (out of 320) who have never heard about EMMs in their village, and thus they have never used health services provided by the EMMs, were found. Those records were removed from further analysis which was aimed to identify the determinants of use of any EMM service, leading to a sample size of 244.

A stepwise backward logistic regression analysis was applied to identify the determinants of utilization of any services provided by EMMs. All potential variables described earlier were initially assessed by chi-square tests. Variables that had $P$-value of chi-square tests $<0.1$ were computed for correlation tests. All variables that had Pearson correlation $<0.75$ were included in the logistic regression. A stepwise backward elimination process was used in multivariate logistic regression. The adjusted odds ratio and $95 \%$ confidence interval (CI) were estimated using the logistic regression coefficient. The goodness-of-fit of the model was assessed using the Hosmer-Lemeshow statistics and pseudo- $R$-squares (Cox and Snell $R$-square and Nagelkerke $R$-square).

\section{Ethical issues}

Ethics clearances for this study were obtained from the Institutional Review Boards of the Hanoi School of Public Health (IRB reference number 281/2014/YTCC-HD3) and of the World Health Organization (Protocol ID: RPC-759). 
Informed consents were obtained from all study participants prior to data collection.

\section{Results}

\section{Characteristics of study participants}

As shown in Table 1, one-fifth of the total 320 respondents were $<20$ years old, and one-third had no previous children before this pregnancy. In relation to ethnicity, $43.4 \%$ of the study participants were Hmong people living in Dien Bien province; $44.4 \%$ of Xo Dang living in Kon Tum; and $12.2 \%$ represented others ethnic groups (Khang, Kho $\mathrm{Mu}, \mathrm{Ba} \mathrm{Na}$, and Gia Rai). Approximately $34.4 \%$ of the study participants never attended school, 55.6\% were the poor, and $\sim 93.1 \%$ had health insurance card. A total of $30 \%$ of respondents lived $>5 \mathrm{~km}$ away from the nearest health facilities, whereas $60 \%$ had reported difficulties in accessing the nearest health facility during rainy seasons.

\section{Maternal EMM service utilization}

Overall, as shown in Table 2, nearly all women used at least one type of maternal health services during their pregnancy, delivery, or postnatal period. However, only $\sim 45.6 \%$ of women used any services provided by EMMs. This proportion

Table I Social demographic characteristics of study participants $(\mathrm{N}=320)$

\begin{tabular}{|c|c|c|}
\hline Characteristics & $\mathbf{n}$ & $\%$ \\
\hline \multicolumn{3}{|l|}{ Age group } \\
\hline$\leq 19$ years & 69 & 21.6 \\
\hline 20-34 years & 227 & 70.9 \\
\hline$\geq 35$ years & 24 & 7.5 \\
\hline \multicolumn{3}{|l|}{ Number of children } \\
\hline 1 & 113 & 35.3 \\
\hline$\geq 2$ & 207 & 64.7 \\
\hline \multicolumn{3}{|l|}{ Ethnic group } \\
\hline Hmong & 139 & 43.4 \\
\hline Xo Dang & 142 & 44.4 \\
\hline Others (Gia Rai, Ba Na, Khang, and Kho Mu) & 39 & 12.2 \\
\hline \multicolumn{3}{|l|}{ Education } \\
\hline No school & 110 & 34.4 \\
\hline Attended school & 210 & 65.6 \\
\hline \multicolumn{3}{|l|}{ Household economic status } \\
\hline Poor & 178 & 55.6 \\
\hline Nonpoor & 142 & 44.4 \\
\hline \multicolumn{3}{|l|}{ Possession of health insurance } \\
\hline Yes & 298 & 93.1 \\
\hline No & 22 & 6.9 \\
\hline \multicolumn{3}{|l|}{ Distance to a nearest health facility } \\
\hline$<5 \mathrm{~km}$ & 225 & 70.3 \\
\hline$\geq 5 \mathrm{~km}$ & 95 & 29.7 \\
\hline \multicolumn{3}{|c|}{ Difficulty in accessing a nearest health facility in rainy season } \\
\hline No & 128 & 40.0 \\
\hline Yes & 192 & 60.0 \\
\hline
\end{tabular}

was lower than services provided by midwives, though higher than services provided by all other health workers such as doctors, nurses, and village health workers.

From the services provided by EMMs, PNC services were the most frequently utilized (33.8\%), followed by ANC (33.4\%) and assistance during delivery (20.3\%). Compared to other health-care providers who were trained in midwifery skills, EMMs had a pivotal role in attending home deliveries ( $21.6 \%$ vs $0.1 \%-6.5 \%$ by other health workers). Of those deliveries at home, $41 \%$ were supported by relatives (such as mother or sisters) and only $4 \%$ were supported by traditional birth attendants. A total of $57.3 \%$ of mothers were visited by an EMM during the postnatal period, as compared with $2.7 \%-22.7 \%$ who received visits from other health workers. Approximately one-third of cases $(26.1 \%-41.2 \%)$ with abnormal signs were referred to higher levels by EMMs, with the percentage being particularly high during the intrapartum period $(41.2 \%)$.

\section{Factors associated with EMM service utilization}

A total of $23.8 \%$ of participants never heard about EMMs in their villages. They, therefore, did not use any EMM services. The number of economically poor mothers who knew about EMM (59\%) was slightly higher than the proportion of poor among all participants $(55.6 \%)$, but this difference was not statically significant (CI: 51\%-61.1\%). All other sociodemographic characteristics between the two groups were checked for differences and were not found to be significant. A total of 244 participants who heard about EMMs were included in further analysis. Characteristics of this group by EMM service utilization are described in Table 3.

\section{Socioeconomic determinants}

Among the selected sociodemographic characteristics, using any EMM services was the only statistically significant difference between ethnic groups $(p<0.05)$. The proportion of mothers of Xo Dang, Ba Na, and Gia Lai ethnicities in KonTum province who used any EMM services (65.5\%) was higher than that of Hmong mothers in Dien Bien province $(52.3 \%)$. The utilization of any EMM services was higher among mothers from poor households, those who attended school, aged $>20$ years, and who had their first child. However, these differences were not statistically significant $(p>0.05)$.

\section{Knowledge and trust in EMM services}

A total of $87.3 \%$ of participants were aware about at least one service provided by EMMs and $26.2 \%$ knew of at least 
Table 2 Utilization of maternal health services by services providers

\begin{tabular}{|c|c|c|c|c|c|c|c|}
\hline \multirow[t]{2}{*}{ Services } & \multirow{2}{*}{\multicolumn{2}{|c|}{$\begin{array}{l}\text { Service } \\
\text { utilization } \\
(\mathrm{n}, \%)\end{array}$}} & \multicolumn{5}{|c|}{ Services provided by } \\
\hline & & & EMM (\%) & Doctor (\%) & Midwife (\%) & $\begin{array}{l}\text { Other health } \\
\text { personnel (\%) }\end{array}$ & $\begin{array}{l}\text { Village health } \\
\text { worker (\%) }\end{array}$ \\
\hline \multicolumn{8}{|l|}{ ANC } \\
\hline$\geq \mathrm{I}$ ANC & 320 & 95.9 & 28.3 & 28.3 & 70.7 & 21.8 & 2.3 \\
\hline Counseling & 320 & 84.7 & 35.8 & 19.5 & 66.9 & 22.1 & 9.9 \\
\hline $\begin{array}{l}\text { Being supported by any health workers in case } \\
\text { of having abnormal signs }\end{array}$ & 36 & 11.3 & 19.4 & 27.8 & 25 & II.I & 5.6 \\
\hline Referred in case of having abnormal signs & 23 & 63.9 & 26.1 & - & - & - & - \\
\hline Any supports in antenatal care services & 320 & 98.4 & 33.4 & 30.6 & 70.3 & 26.6 & 8.8 \\
\hline \multicolumn{8}{|l|}{ Intrapartum care } \\
\hline Home delivery & 320 & 62.2 & 21.6 & 0.1 & 2.0 & 0.5 & 6.5 \\
\hline Birth assisted by health workers & 320 & 56.3 & 16.3 & 19.1 & 23.8 & 6.6 & 4.1 \\
\hline $\begin{array}{l}\text { Being supported by any health workers in case } \\
\text { of having abnormal signs }\end{array}$ & 47 & 14.7 & 17.0 & 42.8 & 38.3 & 17.0 & 2.1 \\
\hline Referred in case of having abnormal signs & 34 & 73.9 & 41.2 & - & - & - & - \\
\hline Any supports in delivery & 320 & 58.4 & 20.3 & 19.7 & 25.3 & 8.4 & 4.4 \\
\hline \multicolumn{8}{|l|}{ Postpartum care } \\
\hline Postnatal counseling & 320 & 73.8 & 37.3 & 11.0 & 26.7 & 9.7 & 22.9 \\
\hline Visits within 42 days after delivery & 320 & 46.9 & 57.3 & 2.7 & 22.7 & 16.0 & 17.1 \\
\hline $\begin{array}{l}\text { Being supported by any health workers in case } \\
\text { of having abnormal signs }\end{array}$ & 320 & 8.8 & 42.9 & 21.4 & 25.0 & 10.7 & 1 \\
\hline $\begin{array}{l}\text { Newborn being supported by any health } \\
\text { workers in case of having abnormal signs }\end{array}$ & 31 & 9.7 & 12.9 & 38.7 & 9.7 & 22.6 & 3.2 \\
\hline Mother/child referred & 34 & 65.4 & 32.4 & - & - & - & - \\
\hline Any postnatal care services & 320 & 79.1 & 33.8 & 12.2 & 24.1 & 13.4 & 23.4 \\
\hline Any services & 320 & 99.4 & 45.6 & 41.9 & 75 & 36.3 & 26.9 \\
\hline
\end{tabular}

Abbreviations: ANC, antenatal care; EMM, ethnic minority midwife.

four services. The majority of participants $(82.4 \%)$ knew that an EMM was trained for providing maternal and child health-care services.

A mother, husband, relative, or friend was the most common source of information about EMMs (48\%), followed by village leaders (32.8\%), village health workers (24.2\%), and health workers (18\%). Approximately $80 \%$ of women reported their perception that many people in the village knew about EMM services, and $72.6 \%$ had trust in most services that were available from EMMs.

The use of any EMM service was a statistically significant difference between groups who knew about EMM services, that EMMs were trained, thought that other mothers in village knew about EMM services, and had trust in EMM services $(P<0.05)$. The more EMM services mothers could list, the more EMM services they used. Among mothers who did not report knowledge of specific services provided by EMMs, $48.9 \%$ used any EMM services compared to 55\% among those who knew less than three services and to $71.9 \%$ among those who knew at least four services. The use of any EMM services was higher among mothers who knew that EMM was trained (62.7\%) than among those who did not know (39.5\%); higher among those who thought that many people in the village knew about EMMs (67.5\%) as compared to those who thought very few or nobody in the village knew about EMMs (24\%); and higher among those who had trust in most services that EMMs provided (63.6\%) than had trust in only some EMM services (42.1\%). Any further utilization of EMM services by other characteristics (such as age, religion, number of children, education, know about EMM services, and source of information about EMM) was not statistically significant.

\section{Ability to reach EMM services}

From all participants, $64.3 \%$ lived $>5 \mathrm{~km}$ away from a nearest health facility, and $65.2 \%$ were living in places that had seasonal difficulties in reaching a nearest health facility. Meanwhile, nearly $89.8 \%$ of mothers knew the location of EMM's house and $78.2 \%$ of them lived $<2 \mathrm{~km}$ from EMM's house. A total of $74.2 \%$ of all mothers reported that they could call EMM for help whenever they needed.

The results of bivariate analysis showed a statistically significant difference in the use of any EMM services by the ability to reach EMMs and road condition to the nearest health facility $(p<0.01)$. Approximately $64.4 \%$ of mothers who knew the location of EMM's house had used any EMM 
Table 3 Bivariate analysis of factors associated with the use of any services provided by EMMs

\begin{tabular}{|c|c|c|c|}
\hline Characteristics & n (\%) & $\begin{array}{l}\text { Using EMM } \\
\text { (yes, n, \%) }\end{array}$ & $\begin{array}{l}P \text {-value } \\
\left(\chi^{2}\right)\end{array}$ \\
\hline \multicolumn{4}{|c|}{ Socioeconomic determinants } \\
\hline \multicolumn{3}{|c|}{ Age group } & 0.839 \\
\hline$<20$ years & $54(22.1)$ & $31(54.7)$ & \\
\hline$\geq 20$ years & $190(77.9)$ & $\mathrm{I} 12(58.9)$ & \\
\hline \multicolumn{3}{|l|}{ Number of children } & 0.385 \\
\hline I & $85(34.8)$ & $53(62.4)$ & \\
\hline$\geq 2$ & $159(65.2)$ & $90(56.6)$ & \\
\hline \multicolumn{3}{|l|}{ Ethnic group } & $0.037^{*}$ \\
\hline Hmong, Kho Mu, Khang & $128(52.5)$ & $67(52.3)$ & \\
\hline Xo Dang, Ba Na, Gia Lai & $116(47.5)$ & $76(65.5)$ & \\
\hline \multicolumn{3}{|l|}{ Education } & $0.096 *$ \\
\hline Never attended school & $82(33.6)$ & $42(5 \mid .2)$ & \\
\hline Attended school & $162(66.4)$ & $101(62.3)$ & \\
\hline \multicolumn{3}{|l|}{ Household economic status } & 0.223 \\
\hline Poor & I 44 (59.0) & $89(61.8)$ & \\
\hline Nonpoor & $100(41.0)$ & $54(54.0)$ & \\
\hline \multicolumn{4}{|c|}{ Knowledge and trust in EMM services } \\
\hline \multicolumn{3}{|c|}{ Knowledge about EMM services } & $0.034 *$ \\
\hline None of services & $31(12.7)$ & $15(48.4)$ & \\
\hline I-3 services & $149(87.3)$ & $128(55.0)$ & \\
\hline$\geq 4$ services & $64(26.2)$ & $46(71.9)$ & \\
\hline \multicolumn{3}{|c|}{ Knowledge that EMM was trained } & $0.005^{*}$ \\
\hline No & $43(17.6)$ & $17(39.5)$ & \\
\hline Yes & $201(82.4)$ & $126(62.7)$ & \\
\hline \multicolumn{4}{|c|}{ Source of information about EMM } \\
\hline \multicolumn{3}{|c|}{ Village leader } & 0.388 \\
\hline No & $164(67.2)$ & $93(56.7)$ & \\
\hline Yes & $80(32.8)$ & $50(62.5)$ & \\
\hline \multicolumn{3}{|l|}{ Village health worker } & 0.277 \\
\hline No & $185(75.8)$ & $112(60.5)$ & \\
\hline Yes & $59(24.2)$ & $31(52.5)$ & \\
\hline \multicolumn{3}{|l|}{ Health worker } & $0.078^{*}$ \\
\hline No & $200(92.0)$ & $\mathrm{II} 2(56.0)$ & \\
\hline Yes & $44(18.0)$ & $31(70.5)$ & \\
\hline \multicolumn{3}{|l|}{ Mother/husband/relative } & 0.121 \\
\hline No & $127(52.0)$ & $92(57.9)$ & \\
\hline Yes & $117(48.0)$ & $51(60.0)$ & \\
\hline \multicolumn{3}{|c|}{$\begin{array}{l}\text { Perception that other mothers in a village know about EMM } \\
\text { services }\end{array}$} & $<0.00 I^{*}$ \\
\hline A few or no one know & $50(20.1)$ & $12(24.0)$ & \\
\hline Many & $194(79.9)$ & $13 \mid(67.5)$ & \\
\hline \multicolumn{3}{|c|}{ Knowing where an EMM house is } & $<0.00 I^{*}$ \\
\hline No & $25(10.2)$ & $2(8.0)$ & \\
\hline Yes & $219(89.8)$ & $|4|(64.4)$ & \\
\hline \multicolumn{3}{|l|}{ Trust in EMM services } & $0.004 *$ \\
\hline \multicolumn{3}{|l|}{ provision } & \\
\hline provision & $187(72.6)$ & $119(63.6)$ & \\
\hline \multicolumn{4}{|l|}{ Accessibility } \\
\hline \multicolumn{3}{|c|}{ Distance to a nearest health facility } & 0.789 \\
\hline$\geq 5 \mathrm{~km}$ & $87(35.7)$ & $50(57.5)$ & \\
\hline$<5 \mathrm{~km}$ & $137(64.3)$ & $93(59.2)$ & \\
\hline
\end{tabular}

(Continued)
Table 3 (Continued)

\begin{tabular}{llll}
\hline Characteristics & $\mathbf{n}(\%)$ & $\begin{array}{l}\text { Using EMM } \\
\text { (yes, } \mathbf{n}, \%)\end{array}$ & $\begin{array}{l}\text { P-value } \\
\left(\chi^{2}\right)\end{array}$ \\
\hline $\begin{array}{l}\text { Difficulty of access to a nearest health facility } \\
\text { during rainy season }\end{array}$ & 0.157 \\
$\quad$ No & $85(34.8)$ & $55(64.7)$ & \\
$\quad$ Yes & $159(65.2)$ & $88(55.3)$ & \\
$\begin{array}{l}\text { Distance to an EMM's house } \\
\geq 2 \mathrm{~km}\end{array}$ & $72(21.8)$ & $33(45.8)$ & \\
$\quad<2 \mathrm{~km}$ & $172(78.2)$ & $110(64.0)$ & \\
$\begin{array}{l}\text { Can call an EMM if needed } \\
\text { No }\end{array}$ & $63(25.8)$ & $17(27)$ & $<0.00 I^{*}$ \\
Yes & $181(74.2)$ & $126(69.6)$ & \\
\hline
\end{tabular}

Note: $* P<0.05$.

Abbreviation: EMM, ethnic minority midwife.

services, as compared to $8 \%$ of those who did not know. A total of $64 \%$ of mothers who lived $<2 \mathrm{~km}$ from EMM's house used any EMM services, a figure that was higher than those who lived $>2 \mathrm{~km}$ away (45.8\%). Approximately $70 \%$ of mothers who used any EMM services reported they could call an EMM whenever they felt the need to, as compared to $27 \%$ of those who could not.

The final model (Table 4) predicted that any EMM service utilization was associated with the following characteristics: knowing about an EMM from health workers, knowing the location of an EMM's house, perception that other mothers in the village who know about EMMs and trust EMM services and ethnicity. All these factors, except

Table 4 Logistic regression analysis of factors associated with using any EMM services $(n=244)$

\begin{tabular}{|c|c|c|}
\hline Variables & $P$-value & aOR $(95 \% \mathrm{Cl})$ \\
\hline \multicolumn{3}{|l|}{ Ethnic group } \\
\hline Xo Dang, Ba Na, Gia Lai & & 1 \\
\hline Hmong, Kho Mu, Khang & 0.65 & $0.53(0.27-1.04)$ \\
\hline \multicolumn{3}{|c|}{ Knowledge about EMMs from health workers } \\
\hline No & & 1 \\
\hline Yes & 0.024 & $2.68(1.14-6.31)$ \\
\hline \multicolumn{3}{|c|}{ Perception that other mothers in a village know about EMMs } \\
\hline A few or no one know & & 1 \\
\hline Many & $<0.001$ & $4.91(2.18-11.04)^{*}$ \\
\hline \multicolumn{3}{|l|}{ Trust in EMM services } \\
\hline Some of service provision & & 1 \\
\hline Most of service provision & 0.002 & $3.36(1.56-7.11)^{*}$ \\
\hline \multicolumn{3}{|c|}{ Knowing the location of an EMM's house } \\
\hline No & & 1 \\
\hline Yes & $<0.001$ & $26.6(5.02-140.7)^{*}$ \\
\hline
\end{tabular}

Notes: $P=0.8$ (Hosmer \& Lemeshow), 0.26 (Cox \& Snell), 0.35 (Nagelkerke). Model $\chi^{2}(7)=3.069 . * P<0.05$.

Abbreviations: $\mathrm{aOR}$, adjusted odds ratio; $\mathrm{Cl}$, confidence interval; $\mathrm{EMM}$, ethnic minority midwife. 
ethnicity, were statically significant determinants of service utilization at $p<0.05$.

Knowing where an EMM is located was the most significant determinant of use of EMM services (adjusted odds ratio [aOR] $=26.6$, CI: 5.0-140.7), whereas other determinants also result in 3-5 times higher likelihood of service utilization from EMMs. Women who perceived that many other women in the village knew about EMMs were 4.9 times more likely to use any EMM services than the others $(\mathrm{aOR}=4.9$, CI: 2.2-11.0). Women who had trust in EMM services were 3.4 times more likely to use any EMM services than those who had not $(\mathrm{aOR}=3.4, \mathrm{CI}$ : 1.6-7.1). Women who knew about EMMs from health workers were 2.7 times more likely to use EMM services than those who did not know about EMMs $(\mathrm{aOR}=2.7, \mathrm{CI}: 1.1-6.3)$.

\section{Discussion}

Our results show that utilization of maternal health services was limited among ethnic minority mothers, particularly the delivery and PNC services. Institutional delivery and skilled birth attendance were among the most evenly distributed between different ethnic groups, a finding that is similar to what has been reported in recent studies. ${ }^{2}$ Home deliveries were preferred among ethnic minority groups as compared with institutional deliveries. ${ }^{3,6}$ Preference for home deliveries among Hmong ethnic group had been well documented elsewhere, for example, in studies of people of Hmong ethnicity living in mountainous region of Vietnam, ${ }^{14}$ in mountainous region of Thailand, ${ }^{15,16}$ or Hmong migrants in the US. ${ }^{17,18}$ Coverage of perspectives on health and health-care utilization of the Xo Dang people was more scarce in the literature, but delivery at home was also their preference. ${ }^{19}$

There are different possible explanations, from both supply and demand sides, for preference for home delivery in ethnic minority groups. ${ }^{4,5,20}$ The introduction of health insurance in Vietnam, although contributed to increasing the antenatal checkup coverage, did not increase the rates of institutional delivery. ${ }^{21}$ Complex rituals surrounding births that are more easily performed at home present a major barrier for institutional delivery to Hmong people. ${ }^{13,14,22}$ A report on Xo Dang people in Kon Tum province also highlighted barriers to maternal health-care utilization such as lack of cultural sensitivity from health workers and linguistics differences. ${ }^{19}$

Although obstetric hemorrhage is the cause of most maternal deaths, ${ }^{23-25}$ and most maternal deaths occurring in postpartum period, ${ }^{23,25} \mathrm{PNC}$ has been generally neglected. ${ }^{26,27}$
In Vietnam, even gray literature on PNC and its determinants among ethnic minority groups is limited. The traditional customs of some ethnic minorities, which prohibit strangers to enter houses with a new deliverer, pose a significant constraint to the provision of PNC. ${ }^{28-33}$

In the settings with low maternal service utilization and strong cultural influences like ethnic minority groups in Vietnam, the presence of EMMs to assist home deliveries could be an effective short-term strategy to improve maternal health outcomes. ${ }^{26}$ Our study showed that EMMs were the main health service provider attending home deliveries and were the second most frequent health worker (only after midwives) attending total deliveries.

We also found that the EMMs also contributed the largest part in providing PNC services. According to their job description from the $\mathrm{MOH}$, the EMMs are expected to encourage women to deliver in health facilities and only assist delivery in cases when mothers do not want or cannot go to the health facility. The EMMs, from this perspective, could be an effective substitute for other health staff in relation to these two tasks. To take advantage of EMMs in providing postnatal services and to improve quality of services provision, training of EMMs should include a focus on PNC and integrated newborn care. In similar contexts, training local people or young women like in Vietnam to become maternal and child health-care providers, for example, traditional birth attendants, can represent an effective strategy to improve access to maternal health services among the hard-to-reach groups such as ethnic minorities.

Utilization of EMM services, however, was still relatively low, as only half of mothers used any EMM services. The low rate of use of EMM services could be partly explained by the limited availability of EMMs in these villages, as only 23 of 31 EMMs had finished their training 5 months prior to the assessment. Women, thus, did not use EMM services mainly because the EMM services were not available during their pregnancy, intra-, and postpartum periods. Awareness about the availability of an EMM in the village was also limited as one-fourth of the respondents had never heard about an EMM and never ever used the EMM services. Awareness about the EMM scheme, therefore, should be substantially increased alongside the expansion of the numbers of EMMs.

Mothers who knew more about EMM services used significantly more EMM services. Positive association between knowledge on maternal health services provision and using maternal services found in this study has also been reported elsewhere, for example, in Vietnam ${ }^{34}$ or in Nepal. ${ }^{35}$ 
However, the association between knowledge on EMM services and using any EMM services is not strong enough to retain this variable in the final model, predicting the use of any EMM services.

Perception that many people in the village know about EMMs potentially reflect social influence on maternal service utilization. Mechanisms of social influence on female reproductive choices in the developing world have been discussed in recent study. ${ }^{36}$ In mountainous villages that had EMMs, social influence may have strongly affected women members as the community network is cohesive, homogeneous, and closed, increasing their likelihood to use similar methods as their network counterparts. ${ }^{36}$

Among those who have heard about the EMMs, knowing where an EMM's house is located was positively associated with the use of EMM services. However, as outlined in the study limitations, our small sample size and large confidence interval mean that our results may not reflect all ethnic minorities in the country. Knowing the location of the EMM's house and perception that many people in the village who knew about EMMs may also have a link with trust in EMM. The study results showed that mothers who had trust in services provided by an EMM were more likely to use any EMM services than those who had not. A recent study also showed that patients from Hmong ethnic group seek trusting relationships and behaviors that demonstrate caring and thus have greater value than only medical skills. ${ }^{15}$ A study in Indonesia supports the idea of importance of shared culture and language by local community members, ${ }^{10}$ the two important components of trust.

Geographical issues and distance may not be the major barriers to access the maternal health-care services, because ethnic minorities often routinely travel long distances to pursue their livelihoods. ${ }^{37}$ However, low service attendance is often ascribed to geographical isolation. ${ }^{2,3,5} \mathrm{We}$ did not find any differences in using any EMM services by distance to a nearest health facility as compared with distance to an EMM's house. The rationale of EMM living in the village can be explained by our finding that most mothers who live within $2 \mathrm{~km}$ from an EMM house expect EMM services to be provided at home.

Mothers, husbands, relatives, or friends were the most common source of information about EMMs. This suggests that target audience for information dissemination should not be limited to pregnant women only, but can also include their relatives and other people in their villages. Even outside the boundaries of our study, we recognize that besides information dissemination the other members of women's family and community can play important roles in women's utilization of EMM services. Examples of such roles include implications on women's family and household duties and commitments and economic flexibility to be able to afford travel to access health services if needed.

We found that utilization of EMM services was not significantly different between mothers who knew about EMMs from those groups and mothers who knew about EMM from others sources, most notably from health workers. Mothers who knew about an EMM from health workers, however, were three times more likely to use EMM services. This suggests that health workers are perceived as a trustworthy and respectable source of information by these women, which can in turn help to increase utilization of health services. Therefore, health workers in the local health facilities can be an important channel for raising awareness about EMMs.

Regarding further strengthening of the EMM scheme, there should be a clear strategy to enhance the dissemination of EMMs' roles within local communities, with contribution from local health centers. The messages should include information on the location of EMM's houses, health services they can provide, and technical support which is available to EMMs. Such information should in turn help to build up trust from local communities to EMMs.

\section{Limitations}

This study was conducted with a small sample size, which limited gaining general estimates of using any EMM services. Key influences on utilization of services found in the study had larger confidence intervals. The analysis of facilitators was among those who heard about EMMs; although we did check for sociodemographic differences between the two groups, we did not find any significant differences. We recognize, however, that this indifference may be due to small sample size. Mothers who used health-care services would more likely come to community health centers to participate in the assessment, which may have introduced potential bias in the collected data. Utilization of maternal services, including those provided by EMMs, therefore, could be lower among the wider community.

\section{Conclusion}

This study assessed the utilization of EMM services by the ethnic minority groups in Vietnam and explored the main facilitators and constraints to this utilization. Overall, the EMM scheme contributed to increased provision of health care during home deliveries and PNC. Health workers need 
to increase sharing of information and communication about EMM services with community members.

\section{Acknowledgments}

This study was financially supported by the WHO Alliance for Health Policy and Systems Research, project HQHSR 1409738 task 2.6, WHO Reference 2015/493716-0. We would like to thank all the study participants for sharing their views and spending time with the researchers and Hanoi School of Public Health, Department of Maternal and Child Health, and Ministry of Health for providing valuable support while conducting this study. We also thank Angela Thedinga, University of North Carolina, for her contribution in data cleaning during her Practicum as a part of her Master of Public Health at the Hanoi School of Public Health.

\section{Disclosure}

The authors report no conflicts of interest in this work.

\section{References}

1. WHO. Trends in Maternal Mortality: 1990 to 2013. Estimates by WHO, UNICEF, UNFPA, The World Bank and the United Nations Population Division. 2014. Available from: http://www.who.int/reproductivehealth/ publications/monitoring/maternal-mortality-2013/en/. Accessed March 26, 2016

2. Axelson H, Gerdtham UG, Ekman B, Dinh TP, Alfven T. Inequalities in reproductive, maternal, newborn and child health in Vietnam: a retrospective study of survey data for 1997-2006. BMC Health Serv Res. 2012;12:456.

3. Goland E, Hoa DTP, Målqvist M. Inequity in maternal health care utilization in Vietnam. Int J Equity Health. 2012;11:24-24.

4. Malqvist M, Hoa DT, Liem NT, Thorson A, Thomsen S. Ethnic minority health in Vietnam: a review exposing horizontal inequity. Glob Health Action. 2013;6:1-19.

5. Malqvist M, Hoa DT, Thomsen S. Causes and determinants of inequity in maternal and child health in Vietnam. BMC Public Health. 2012;12:641.

6. Malqvist M, Lincetto O, Du NH, Burgess C, Hoa DT. Maternal health care utilization in Viet Nam: increasing ethnic inequity. Bull World Health Organ. 2013;91(4):254-261.

7. Mai BTT, Minh TH, Linh DTH, et al. Pilot model: 18 month training of ethnic minority midwives; 2011. Available from: http://healthmarketinnovations.org/sites/default/files/Ethnic\%20Minority\%20 Midwives\%20Training\%20Pilot\%20Case\%20Study.pdf. Accessed March 26, 2016.

8. Vietnam Ministry of Health. Health Statistical Yearbook 2014. 2014.

9. Sakeah E, Doctor HV, McCloskey L, Bernstein J, Yeboah-Antwi K, Mills S. Using the community-based health planning and services program to promote skilled delivery in rural Ghana: socio-demographic factors that influence women utilization of skilled attendants at birth in northern Ghana. BMC Public Health. 2014;14:344.

10. Titaley CR, Hunter CL, Dibley MJ, Heywood P. Why do some women still prefer traditional birth attendants and home delivery? A qualitative study on delivery care services in West Java Province, Indonesia. BMC Pregnancy Childbirth. 2010;10:43.

11. Harris A, Zhou Y, Liao H, Barclay L, Zeng W, Gao Y. Challenges to maternal health care utilization among ethnic minority women in a resource-poor region of Sichuan Province, China. Health Policy Plan. 2010;25(4):311-318.
12. Gyaltsen Gongque Jianzan K, Gyal Li Xianjia L, Gipson JD, Kyi Cai Rangji T, Pebley AR. Reducing high maternal mortality rates in western China: a novel approach. Reprod Health Matters. 2014;22(44):164-173.

13. Fugmann L. Ethnic midwives of Meo Vac, Vietnam - their influence on reproductive health perspectives and practices among Hmong women. 2013.

14. White J, Oosterhoff P, Huong NT. Deconstructing 'barriers' to access: minority ethnic women and medicalised maternal health services in Vietnam. Glob Public Health. 2012;7(8):869-881.

15. Culhane-Pera KA, Sriphetcharawut S, Thawsirichuchai R, Yangyuenkun W, Kunstadter P. Afraid of delivering at the hospital or afraid of delivering at home: a qualitative study of Thai Hmong families' decision-making about maternity services. Matern Child Health J. 2015;19:2384-2392.

16. Spring MA, Ross PJ, Etkin NL, Deinard AS. Sociocultural factors in the use of prenatal care by Hmong women, Minneapolis. Am J Public Health. 1995;85(7):1015-1017.

17. Halvorsen T. Pregnancy and birth in Minnesota's Hmong population: changing practices. Minnesota Med. 2012;95(5):49-52.

18. Luce H, Redmer J, Gideonsen M, Dresang L, Potter B, Schrager S. Culturally specific maternity care in Wisconsin. WMJ. 2011;110(1):32-37.

19. Bale B. Rapid Maternal and Neonatal Health Care Needs Assessment in UNFPA Supported Provinces of Vietnam Hanoi: PATH;2006.

20. Axelson H, Bales S, Minh PD, Ekman B, Gerdtham UG. Health financing for the poor produces promising short-term effects on utilization and out-of-pocket expenditure: evidence from Vietnam. Int $J$ Equity Health. 2009;8:20.

21. Sepehri A, Sarma S, Simpson W, Moshiri S. How important are individual, household and commune characteristics in explaining utilization of maternal health services in Vietnam? Soc Sci Med. 2008;67(6):1009-1017.

22. UNFPA. Knowledge and Behaviour of Ethnic Minorities on Reproductive Health. Hanoi: UNFPA; 2007.

23. Ronsmans C, Graham WJ. Maternal mortality: who, when, where, and why. Lancet. 2006;368(9542):1189-1200.

24. Khan KS, Wojdyla D, Say L, Gülmezoglu AM, Van Look PFA. WHO analysis of causes of maternal death: a systematic review. Lancet 2006;367(9516):1066-1074.

25. Say L, Chou D, Gemmill A, et al. Global causes of maternal death: a WHO systematic analysis. Lancet Glob Health. 2014;2(6):e323-e333.

26. Campbell OM, Graham WJ. Strategies for reducing maternal mortality: getting on with what works. Lancet. 2006;368(9543):1284-1299.

27. Kerber KJ, de Graft-Johnson JE, Bhutta ZA, Okong P, Starrs A, Lawn JE. Continuum of care for maternal, newborn, and child health: from slogan to service delivery. Lancet. 2007;370(9595):1358-1369.

28. Save Children/US, Path. The Understanding, Awareness, and Practices of Pregnancy, Childbirth and New Born Care. A Research Study Conducted in Pakoh and Van Kieu Ethnic Minority Communities in Dakrong District, Quang Tri Province. Save the Children/US, Path; 2003.

29. Enfants \& Développement. Early Childhood Development in Remote Mountainous Ethnic Minority Communities in Northern Vietnam. Report on the Baseline Survey on Knowledge, Attitudes and Practices on Care for Young Children in Si Ma Cai District, Lao Cai Province. Hanoi: Enfants \& Développement; 2004.

30. Phuong DT, Ha NH, Ky ND. Assessment of the knowlede and practice on reproductive health care of mothers having child under 1 year old in 3 communes of Phu Luong, Thai Nguyen. $J$ Pract Med. 2004; $10: 50-54$

31. Center for Social Development Studies. Traditional beliefs, customs and practices surrounding care for pregnancy and delivery among ethinic women in Nghe An Province. Centre for social development studies (CSDS); Hanoi 2005.

32. Man NV, Ha NT, Nga PQ, Quang LN, Hung TQ. The Survey on Ability of Approach, Utilization and Quality of Health Care Service for Maternal During Pregnant and Delivery Period in 2004. Hanoi: Hanoi School of Public Health; 2006. 
33. Hoa DTP, Binh TH. Seeking and Health Care Utilization Behaviour on Reproductive Health Care of Ethnic Women in Tay Nguyen. Hanoi: Department of Reproductive Health - Ministry of Health, Vietnam Scientific and Social Institute; 2007.

34. Ha BT, Tac PV, Duc DM, Duong DT, Thi le M. Factors associated with four or more antenatal care services among pregnant women: a crosssectional survey in eight South Central Coast provinces of Vietnam. Int J Women's Health. 2015;7:699-706.

35. Deo KK, Paudel YR, Khatri RB, et al. Barriers to utilization of antenatal care services in Eastern Nepal. Frontiers in Public Health. 2015;3:197.
36. Lowe SMP, Moore S. Social networks and female reproductive choices in the developing world: a systematized review. Reprod Health. 2014;11:85.

37. UNFPA. Research on Reproductive Health in Vietnam: A Review for the Period 2000-2005. 2007. Available from: http://vietnam.unfpa. org/publications/research-reproductive-health-viet-nam-review-period2000-2005. Accessed March 26, 2016.

International Journal of Women's Health

Dovepress

\section{Publish your work in this journal}

The International Journal of Women's Health is an international, peerreviewed open-access journal publishing original research, reports, editorials, reviews and commentaries on all aspects of women's healthcare including gynecology, obstetrics, and breast cancer. The manuscript management system is completely online and includes

a very quick and fair peer-review system, which is all easy to use. Visit http://www.dovepress.com/testimonials.php to read real quotes from published authors.

Submit your manuscript here: http://www.dovepress.com/international-journal-of-womens-health-journal 